\title{
LƯợNG BÓN ĐẠT HIỆU QUẢ KINH TẾ CAO CHO NGÔ LAI TRUNG NGÀY CP 333 TRÊN ĐẤT BẠC MÀU TỈNH BẮC GIANG
}

\author{
Đinh Văn Phóng, ${ }^{1,}$, Nguyễn Như Hà ${ }^{2}$ Nguyễn Văn Bọ̣ ${ }^{3}$ \\ ${ }^{l}$ Công ty TNHH Hạt giống CP Việt Nam \\ ${ }^{2}$ Trường Đại học Nông nghiệp Hà Nội \\ ${ }^{3}$ Viện Khoa hoc Nông nghiệp Việt Nam \\ *Email: phongcps@yahoo.com.vn
}

Đến Toà soạn: 15/3/2013; Chấp nhận đăng: 29/8/2013

\section{TÓM TĂT}

Kết quả thí nghiệm đối với giống ngô lai trung ngày $\mathrm{CP} 333$ trên đất bạc màu nghèo chất hữu cơ, nghèo chất dinh dưỡng Bắc Giang cho thây: Trên cơ sở mật độ 7 vạn cây/ha, khoảng cách hàng $50 \mathrm{~cm}$ lượng bón đạt hiệu quả kinh tế cao nhất là 10 tấn phân chuồng $+176 \mathrm{~kg} \mathrm{~N}+$ $117 \mathrm{~kg} \mathrm{P} \mathrm{P}_{2} \mathrm{O}_{5}+130 \mathrm{~kg} \mathrm{~K} \mathrm{~K}_{2} \mathrm{O} / \mathrm{ha}$. Với mức bón này ngô sinh trưởng phát triển tốt, năng suất ngô xuân có thể đạt $8260 \mathrm{~kg} / \mathrm{ha}$ và năng suất ngô đông có thể đạt 6493 - 7390 (bình quân: 6941 $\mathrm{kg} / \mathrm{ha}$ ). Lợi nhuận thuần trên mỗi ha có thể đạt 28517000 đồng đối với ngô xuân và 15971000 24293000 đồng đối với ngô đông.

Tù̀ khoá: ngô lai, đất bạc màu, phân bón.

\section{1. ĐẶT VẦn ĐỀ}

Ở Việt Nam, ngô là cây lương thực có vị trí thứ 2 (sau lúa), là cây trồng hàng hóa quan trọng ở các vùng sinh thái. Ngô hiện được dùng chủ yếu làm nguyên liệu cho công nghiệp chế biến thức ăn chăn nuôi và là nguyên liệu lí tưởng để tạo ra năng lượng sinh học.

Theo dự đoán nhu cầu ngô thế giới sẽ là 852 triệu tấn vào năm 2020 [1], tăng $45 \%$ so với năm 1997, riêng với khu vực Đông Nam Á nhu cầu tăng 70 \% so với năm 1997 [2]. Nhu cầu ngô của toàn thế giới tập trung trên $80 \%$ ở các nước đang phát triển và chỉ khoảng $10 \%$ từ các nước công nghiệp [3]. Các nước đang phát triển sẽ phải tự đáp ứng nhu cầu của mình trên diện tích ngô hầu như không tăng [4].

Ngành sản xuất ngô đã có từ lâu ở nước ta và thực sự có những bước tiến nhảy vọt là từ đầu những năm 1990, gắn liền với việc mở rộng diện tích trồng giống lai và các nghiên cứu hoàn thiện các biện pháp kĩ thuật canh tác. Tuy nhiên hiện tại nước ta vẫn phải nhập khẩu 500.000 700.000 tấn ngô hạt/năm, do sản xuất ngô đang có một số tồn tại lớn: Năng suất ngô trung bình (TB) của Việt Nam tuy đã tăng liên tục trong 20 năm gần đây, nhưng cho đến năm 2010 mới đạt 4,09 tấn/ha sản lượng trên 4,6 triệu tấn [5], bằng 80,8 \% năng suất trung bình của thế giới [6], thấp hơn rất nhiều so với các nước năng suất cao $(8-10$ tấn/ha) và với năng suất trong thí 
nghiệm. Giá thành ngô hạt ở Việt Nam còn quá cao nên người sản xuất ngô không có lãi hay lãi ít. Nguyên nhân do nông dân trồng ngô thường mới chỉ quan tâm sử dụng giống ngô lai mà chưa quan niệm đầy đủ mỗi giống phải có mật độ hợp lí để tận dụng ánh sáng, một mức phân thích hợp để phát huy hết tiềm năng của giống và tài nguyên đất.

Để đáp ứng nhu cầu sử dụng ngô hạt trong nước ngày càng tăng và tiến tới xuất khẩu, ngoài việc đưa các giống ngô lai trung ngày có tiềm năng năng suất cao phù hợp cho việc thâm canh tăng vụ ở các vùng sinh thái. Cần nghiên cứu, áp dụng tổng hợp các biện pháp kĩ thuật tiên tiến, trong đó nâng cao mức bón phân cân đối trên cơ sở mật độ và khoảng cách gieo trồng ngô hợp lí cho các vùng sinh thái và đất khác nhau có vai trò đặc biệt để nâng cao năng suất và hiệu quả sản xuất ngô. Dưới đây là kết quả xác định lượng bón đạt hiệu quả kinh tế cao cho ngô lai trung ngày CP333 trên đất xám bạc màu tỉnh Bắc Giang.

\section{VậT LIỆU VÀ PHƯƠNG PHÁP NGHIÊN CỨU}

\subsection{Vật liệu}

Nghiên cứu được thực hiện trên đất xám bạc màu với giống ngô lai CP333 (giống phổ biến ở địa phương).

Các loại phân bón được sử dụng trong thí nghiệm là phân chuồng, đạm urê $46 \% \mathrm{~N}$, supe lân Lâm Thao $16 \% \mathrm{P}_{2} \mathrm{O}_{5}$, kali clorua $60 \% \mathrm{~K}_{2} \mathrm{O}$.

\subsection{Phương pháp nghiên cứu}

Thí nghiệm được thực hiện liên tiếp trong 3 vụ: vụ đông 2010 - vụ xuân 2011 - vụ đông 2011 tại Trung tâm nghiên cứu đất và phân bón vùng trung du (Hiệp Hoà - Bắc Giang). Thí nghiệm gồm 5 công thức, 4 lần nhắc sắp xếp theo kiểu khối ngẫu nhiên hoàn chỉnh (RCBD). Ngô trồng trong thí nghiệm với mật độ 7 vạn cây/ha $(50 \times 28 \mathrm{~cm})$. Lấy nền là 10 tấn phân chuồng, phân NPK ti lệ $1: 0,67: 0,74$ đã được xác định là tối thích cho đất xám bạc màu, tăng từ $115 \mathrm{~N}+77 \mathrm{P}_{2} \mathrm{O}_{5}+85 \mathrm{~K}_{2} \mathrm{O}$ dến $196 \mathrm{~N}+131 \mathrm{P}_{2} \mathrm{O}_{5}+145 \mathrm{~K}_{2} \mathrm{O} .\left(1 \mathrm{NPK}=135 \mathrm{~N}+90 \mathrm{P}_{2} \mathrm{O}_{5}+\right.$ $100 \mathrm{~K}_{2} \mathrm{O}$ ):

\begin{tabular}{|c|c|}
\hline CTTN & Lượng phân bón/ha \\
\hline 1 & Nè̀n $+0,85$ NPK \\
\hline 2 & Nền +1 NPK \\
\hline 3 & Nền $+1,15$ NPK \\
\hline 4 & Nền $+1,30$ NPK \\
\hline 5 & Nền $+1,45$ NPK \\
\hline
\end{tabular}

Phương pháp bón phân: Bón lót toàn bộ phân chuồng và phân lân $+25 \% \mathrm{~N}+25 \% \mathrm{~K}_{2} \mathrm{O}$; Bón thúc lần 1 (giai đoạn 4 - 6 lá): $40 \% \mathrm{~N}+25 \% \mathrm{~K}_{2} \mathrm{O}$; Bón thúc lần 2 (giai đoạn 9 - 12 lá): $35 \% \mathrm{~N}+50 \% \mathrm{~K}_{2} \mathrm{O}$.

Đất thí nghiệm chua $\left(\mathrm{pH}_{\mathrm{KCl}}=4,82\right)$, nghèo mùn $(\mathrm{OM}=1,95 \%)$, đạm $(0,08 \%$,), lân $(0,07 \%)$, kali $(0,72 \%)$ tồng số và kali trao đồi $(7,2 \mathrm{mg} / 100 \mathrm{~g})$ đất.

Các chỉ tiêu sinh truởng: Chiều cao, số lá, chỉ số diện tích lá (LAI) vào các giai đoạn: 3 - 4 lá, 7 - 9 lá, xoáy nõn, thu hoạch. Khả năng chống sâu đục thân và bệnh khô vằn hại cây. 
Các yếu tố cấu thành năng suất và năng suất gồm: Số hạt trung bình/bắp, khối lượng 1000 hạt (gam), năng suất thực thu ( $\mathrm{kg} / \mathrm{ha})$.

Xác định hiệu quả kinh tế

Lãi (thu nhập thuần) = Tổng thu nhập/ha - chi phí vật chất (giống, phân bón, thuốc BVTV, xăng dầu) - chi phí công lao động (tổng số công lao động $\times$ giá 1 công lao động tại địa phương).

Trong đó: Tổng thu nhập/ha = Năng suất ngô và phụ phẩm $(\mathrm{kg} / \mathrm{ha}) \times$ giá (đồng/kg).

Các chỉ tiêu theo dõi, phân tích theo các phương pháp chuẩn và phổ biến hiện nay.

\subsection{Phương pháp xử lí số liệu}

Xử lí thống kê năng suất ngô bằng phân tích phương sai theo phần mềm IRRISTAT 5.0 for Windows.

\section{KẾT QUẢ VÀ THẢO LUẬN}

\section{1. Ảnh hưởng của việc tăng lượng NPK bón đến sinh trưởng, phát triển cây ngô lai trung ngày trên đất xám bạc màu}

Để xác định mức phân bón NPK hợp lí cho thâm canh ngô lai trung ngày ở mật độ 7 vạn cây/ha với khoảng cách hàng $50 \mathrm{~cm}$, chúng tôi đã tiến hành thí nghiệm về ảnh hưởng của việc bón tăng NPK theo cùng tỉ lệ đến sinh trưởng, phát triển và năng suất cây ngô lai trung ngày trên đất xám bạc màu vụ đông 2010, vụ xuân 2011 và vụ đông 2011.

\subsubsection{Anh hưởng của việc tăng lương NPK bón đến phát triển chiều cao, số lá của cây ngô}

Kết quả nghiên cứu cho thấy: Trên nền 10 tấn $\mathrm{PC} /$ ha, khi bón tăng phân NPK cùng tỉ lệ từ 0,85 - 1,45 NPK, tại mỗi thời kì sinh trưởng, chiều cao cây ngô có xu hướng tăng khá rõ, trong đó 2 giai đoạn có sự chênh lệch lớn là giai đoạn 7 - 9 lá, bón 0,85 NPK (CT1) với bón 1,45 NPK (CT5) và càng rõ ở giai đoạn cây ngô xoáy nõn. Bón tăng phân NPK ảnh không nhiều đến phát triển lá của cây ngô, tuy nhiên ở 2 giai đoạn cây ngô 7 - 9 lá và xoáy nõn tác dụng của việc bón phân đến phát triển số lá có phần rõ hơn khi so sánh các CTTN bón 0,85 NPK (CT1) với CTTN bón 1,45 (CT5) (bảng 1a, bảng 1b).

Bảng $1 a$. Tăng trưởng chiều cao của cây ngô qua các giai đoạn theo dõi.

\begin{tabular}{|c|c|c|c|c|c|c|c|c|c|}
\hline \multirow{3}{*}{$\begin{array}{l}\mathbf{C} \\
\mathbf{T} \\
\mathbf{T} \\
\mathbf{N}\end{array}$} & \multirow{3}{*}{ Phân bón } & \multicolumn{8}{|c|}{ Chiều cao cây qua các giai đoạn theo dõi $(\mathrm{cm})$} \\
\hline & & \multicolumn{2}{|c|}{3 - 4 lá } & \multicolumn{2}{|c|}{7 - 9 lá } & \multicolumn{2}{|c|}{ Xoáy nõn } & \multicolumn{2}{|c|}{ Chín sữa } \\
\hline & & $\begin{array}{l}\text { Đông } \\
2010\end{array}$ & $\begin{array}{l}\text { Xuân } \\
2011\end{array}$ & $\begin{array}{l}\text { Đông } \\
2010\end{array}$ & $\begin{array}{l}\text { Xuân } \\
2011\end{array}$ & $\begin{array}{l}\text { Đông } \\
2010\end{array}$ & $\begin{array}{l}\text { Xuân } \\
2011\end{array}$ & $\begin{array}{l}\text { Đông } \\
2010\end{array}$ & $\begin{array}{l}\text { Xuân } \\
2011\end{array}$ \\
\hline 1 & Nền+0,85 NPK & 28,7 & 28,6 & 80,5 & 98,2 & 150,3 & 189,0 & 180,7 & 206,9 \\
\hline 2 & Nền+1,0 NPK & 30,3 & 29,2 & 83,5 & 102,0 & 170,4 & 198,3 & 189,5 & 212,6 \\
\hline 3 & Nền+1,15 NPK & 31,9 & 29,9 & 87,6 & 105,3 & 178,1 & 202,7 & 197,5 & 224,2 \\
\hline 4 & Nền+1,30 NPK & 32,9 & 30,5 & 98,0 & 108,2 & 188,5 & 205,7 & 206,7 & 226,3 \\
\hline 5 & Nền+1,45 NPK & 34,1 & 30,7 & 100,5 & 110,4 & 192,5 & 206,3 & 212,4 & 229,1 \\
\hline
\end{tabular}


Bảng $1 b$. Tăng trưởng số lá qua các giai đoạn theo dõi.

\begin{tabular}{|c|c|c|c|c|c|c|c|c|c|}
\hline $\mathbf{C}$ & & & Số & của cây & $\hat{\text { o qua c }}$ & giai đo & leo dõi & cây) & \\
\hline $\mathbf{T}$ & Dĥ̂n hón & & & & & & & Chi & \\
\hline $\mathbf{N}$ & & $\begin{array}{l}\text { Đông } \\
2010\end{array}$ & $\begin{array}{l}\text { Xuân } \\
2011\end{array}$ & $\begin{array}{l}\text { Đông } \\
2010\end{array}$ & $\begin{array}{l}\text { Xuân } \\
2011 \\
\end{array}$ & $\begin{array}{l}\text { Đông } \\
2010 \\
\end{array}$ & $\begin{array}{l}\text { Xuân } \\
2011\end{array}$ & $\begin{array}{l}\text { Đông } \\
2010\end{array}$ & $\begin{array}{l}\text { Xuân } \\
2011 \\
\end{array}$ \\
\hline 1 & Nền $+0,85$ NPK & 3,9 & 4,0 & 8,6 & 8,5 & 11,6 & 13,3 & 14,0 & 15,8 \\
\hline 2 & Nền $+1,0$ NPK & 4,0 & 4,1 & 8,9 & 8,8 & 12,5 & 13,8 & 14,1 & 15,9 \\
\hline 3 & Nền $+1,15$ NPK & 4,0 & 4,1 & 8,9 & 8,8 & 10,4 & 13,2 & 14,0 & 15,9 \\
\hline 4 & Nền $+1,30$ NPK & 4,0 & 4,1 & 8,9 & 8,9 & 12,3 & 13,8 & 14,0 & 15,9 \\
\hline 5 & Nền + 1,45 NPK & 4,0 & 4,1 & 8,9 & 8,9 & 12,5 & 13,8 & 14,0 & 15,8 \\
\hline
\end{tabular}

Bảng 2. Ảnh hưởng của tăng lượng NPK bón đến sinh trưởng phát triển cây ngô lai vụ đông 2011.

\begin{tabular}{|c|c|c|c|c|c|c|c|c|c|}
\hline \multirow{3}{*}{$\begin{array}{l}\mathrm{C} \\
\mathrm{T} \\
\mathrm{T} \\
\mathrm{N}\end{array}$} & \multirow{3}{*}{ Phân bón/ha; } & \multicolumn{8}{|c|}{ Giai đoạn theo dõi } \\
\hline & & \multicolumn{2}{|c|}{ 3-4 lá } & \multicolumn{2}{|c|}{7 -9 lá } & \multicolumn{2}{|c|}{ Xoáy nõn } & \multicolumn{2}{|c|}{ Chín Sữa } \\
\hline & & $\begin{array}{l}\text { Chiều cao } \\
\text { cây }(\mathrm{cm})\end{array}$ & Số lá/cây & $\begin{array}{l}\text { Chiều cao } \\
\text { cây }(\mathrm{cm})\end{array}$ & Số lá/cây & $\begin{array}{l}\text { Chiều cao } \\
\text { cây }(\mathrm{cm})\end{array}$ & Số lá/cây & $\begin{array}{l}\text { Chiều cao } \\
\text { cây }(\mathrm{cm})\end{array}$ & \begin{tabular}{|c|}
$\begin{array}{c}\text { Số } \\
\text { lá/cây }\end{array}$ \\
\end{tabular} \\
\hline 1 & Nền + 1,0 NPK & 32,9 & 3,5 & 94,1 & 8,7 & 179,1 & 12,2 & 199,7 & 14,7 \\
\hline 2 & Nền $+1,15$ NPK & 34,8 & 3,7 & 96,9 & 8,9 & 181,9 & 12,4 & 203,3 & 14,5 \\
\hline 3 & Nền + 1,3 NPK & 36,3 & 3,6 & 98,9 & 8,8 & 184,4 & 12,5 & 207,5 & 14,7 \\
\hline 4 & Nền $+1,45$ NPK & 37,6 & 3,8 & 99,2 & 8,9 & 186,3 & 12,5 & 209,9 & 14,6 \\
\hline 5 & Nền + 1,60 NPK & 37,3 & 3,6 & 100,4 & 8,9 & 188,6 & 12,4 & 210,5 & 14,7 \\
\hline
\end{tabular}

Kết quả nghiên cứu vụ ngô đông năm 2011 cho thấy, khi bón tăng lượng phân NPK đã làm tăng chiều cao cây ở cả 4 giai đoạn theo dõi nhưng ít ảnh hưởng số lá ngô/cây. Chiều cao cây đạt cực đại ở giai đoạn chín sữa dao động 199,7-210,5 cm. Bón (CT3) chiều cao cây và số lá tương đương (CT4) bón (bảng 2). Kết quả này cũng tương tự các vụ nghiên cứu trước.

\subsubsection{Anh hưởng của việc tăng lương NPK bón đến phát triển chỉ số diện tích lá của cây ngô}

Bảng 3. Ảnh hưởng của việc bón NPK tăng cùng tỉ lệ đến chỉ số diện tích lá.

\begin{tabular}{|c|c|c|c|c|c|c|c|c|c|}
\hline \multirow{3}{*}{$\begin{array}{l}\mathbf{C} \\
\mathbf{T} \\
\mathbf{T} \\
\mathbf{N}\end{array}$} & \multirow{3}{*}{ Phân bón/ha } & \multicolumn{8}{|c|}{ Chỉ số diện tích lá ở các giai đoạn sinh trưởng ( $\mathrm{m}^{2} \mathrm{lá} / \mathrm{m}^{2}$ đất) } \\
\hline & & \multicolumn{2}{|c|}{3 - 4 lá } & \multicolumn{2}{|c|}{7 - 9 lá } & \multicolumn{2}{|c|}{ Xoáy nõn } & \multicolumn{2}{|c|}{ Chín sữa } \\
\hline & & $\begin{array}{l}\text { Đông } \\
2010\end{array}$ & $\begin{array}{l}\text { Xuân } \\
2011\end{array}$ & $\begin{array}{l}\text { Đông } \\
2010\end{array}$ & $\begin{array}{l}\text { Xuân } \\
2011\end{array}$ & $\begin{array}{l}\text { Đông } \\
2010\end{array}$ & $\begin{array}{l}\text { Xuân } \\
2011\end{array}$ & $\begin{array}{l}\text { Đông } \\
2010\end{array}$ & $\begin{array}{l}\text { Xuân } \\
2011\end{array}$ \\
\hline 1 & Nền $+0,85$ NPK & 0,33 & 0,39 & 0,78 & 0,91 & 3,79 & 3,84 & 3,87 & 4,01 \\
\hline 2 & Nền $+1,0$ NPK & 0,55 & 0,56 & 1,36 & 1,41 & 3,98 & 4,66 & 4,08 & 4,83 \\
\hline 3 & Nền $+1,15$ NPK & 0,61 & 0,68 & 1,53 & 1,70 & 4,12 & 4,74 & 4,24 & 4,93 \\
\hline 4 & Nền + 1,30 NPK & 0,72 & 0,76 & 1,78 & 1,90 & 4,38 & 5,01 & 4,53 & 5,23 \\
\hline 5 & Nền + 1,45 NPK & 0,74 & 0,77 & 1,85 & 1,97 & 4,47 & 5,18 & 4,66 & 5,43 \\
\hline
\end{tabular}


Trên đất xám bạc màu ngô đông và ngô xuân, trên nền phân bón 10 tấn $\mathrm{PC} /$ ha, khi bón tăng lượng phân NPK cho cây ngô chỉ sô diện tích lá ở cả 4 giai đoạn đều tăng và đạt cực đại ở giai đoạn chín sữa: Vụ đông là 3,87 - 4,66 m² lá/m² đất, CT4 bón 1,3 NPK là 4,53; Vụ xuân là 4,01 $5,43 \mathrm{~m}^{2}$ lá $/ \mathrm{m}^{2}$ đất và $\mathrm{CT} 4$ là 5,23 . Như vậy, tốc độ tăng chỉ số diện tích lá có xu hướng tỉ lệ thuận với tốc độ tăng lượng phân bón, đặc biệt rõ ở mức bón lớn hơn 1,3 NPK ở cả 2 vụ. Kết quả vụ đông 2011 tương tự các vụ trước trong cùng điều kiện thâm canh. Chỉ số diện tích lá của công (CT3) lá 4,68 tương đương ( CT4,5) là 4,70 - 4,73 (bảng 4).

Bảng 4. Ảnh hưởng của tăng lượng NPK bón theo cùng tỉ lệ cho ngô đến chỉ số diện tích lá ngô vụ đông 2011.

\begin{tabular}{|c|c|c|c|c|c|}
\hline \multirow{2}{*}{$\begin{array}{l}\mathrm{CT} \\
\mathrm{TN}\end{array}$} & \multirow{2}{*}{ Phân bón/ha } & \multicolumn{4}{|c|}{ LAI ở các giai đoạn sinh trưởng ( $\mathrm{m}^{2} \mathrm{lá} / \mathrm{m}^{2}$ đất) } \\
\hline & & 3 - 4 lá & 7 - 9 lá & Xoáy nõn & Chín sữa \\
\hline 1 & Nền $+1,0$ NPK & 0,50 & 1,37 & 4,22 & 4,49 \\
\hline 2 & Nền $+1,15$ NPK & 0,52 & 1,40 & 4,29 & 4,60 \\
\hline 3 & Nền $+1,3$ NPK & 0,60 & 1,50 & 4,35 & 4,68 \\
\hline 4 & Nền $+1,45$ NPK & 0,63 & 1,52 & 4,37 & 4,70 \\
\hline 5 & Nền + 1,60 NPK & 0,64 & 1,54 & 4,39 & 4,73 \\
\hline
\end{tabular}

Như vậy việc tăng lượng NPK bón cho ngô trên đất xám bạc màu có ảnh hưởng tốt đến LAI của cây ngô, tuy nhiên ảnh hưởng tốt hơn ở mức bón 1,3 NPK. Điều này ảnh hưởng tốt đến năng suất ngô sau này.

\section{2. Ảnh hưởng của việc tăng lượng NPK bón đến tình hình sâu bệnh hại cây ngô}

Trên đất xám bạc màu trong cả 2 vụ ngô đông và ngô xuân, trên nền 10 tấn $\mathrm{PC} /$ ha, khi bón tăng NPK từ 0,85 - 1,45 NPK tuy mật độ sâu và tî lệ bệnh có xu hướng tăng nhẹ song không vượt quá ngưỡng phòng trừ. Mức độ sâu và tỉ lệ bệnh hại (CT4) bón 1,3 NPK tương đương (CT2) bón 1 NPK và thấp hơn khá nhiều công thức (CT5) bón 1,45 NPK ở cả 2 vụ (hình 1a và hình 1b).

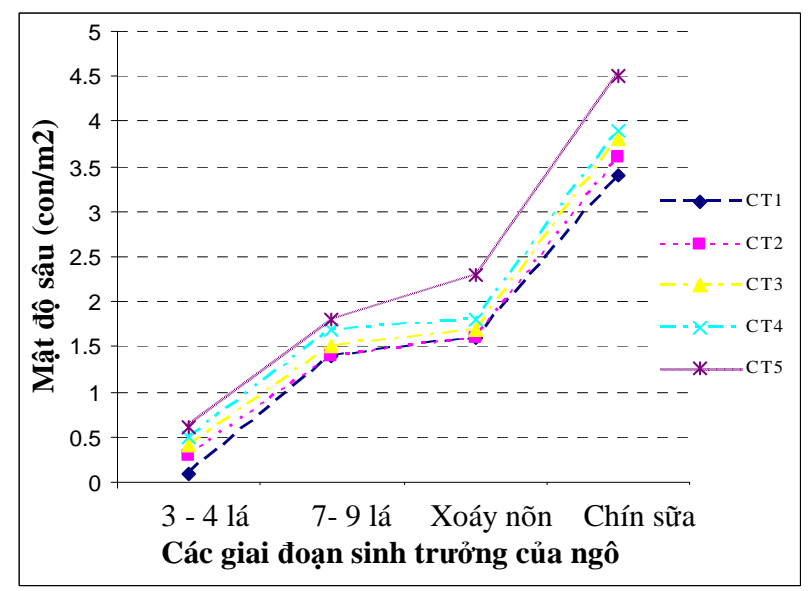

Hình la. Mức độ sâu đục thân hại ngô.

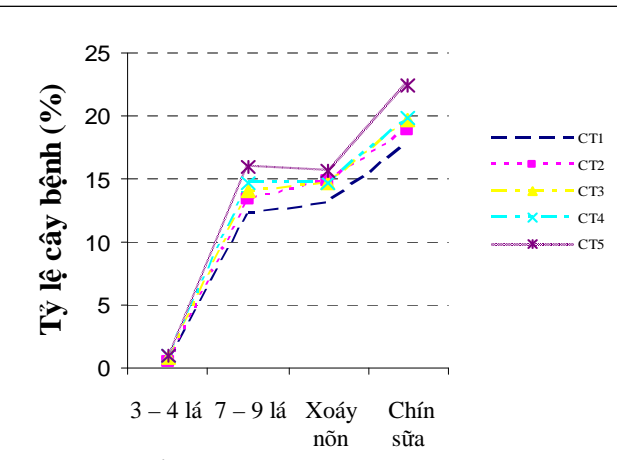

Các giai đoạn theo dõi

Hình $1 b$. Mức độ bệnh khô vằn hại ngô. 


\section{3. Ảnh hưởng của việc tăng lượng NPK bón đến các yếu tố cấu thành năng suất và năng suất ngô}

3.3.1. Anh huởng của việc tăng lương NPK bón đến các yếu tố cấu thành năng suất

Bảng 5. Ảnh hưởng của việc tăng lượng NPK bón đến các yếu tố cấu thành năng suất.

\begin{tabular}{|c|c|c|c|c|c|c|c|c|c|}
\hline \multirow{4}{*}{$\begin{array}{l}\mathrm{C} \\
\mathrm{T} \\
\mathrm{T} \\
\mathrm{N}\end{array}$} & \multirow{4}{*}{ Phân bón/ha } & \multicolumn{4}{|c|}{ Số hạt/bắp } & \multicolumn{4}{|c|}{ Khối lượng 1000 hạt (g) } \\
\hline & & \multirow{2}{*}{\multicolumn{2}{|c|}{$\begin{array}{l}\text { Đông } \\
2010\end{array}$}} & \multirow{2}{*}{\multicolumn{2}{|c|}{$\begin{array}{l}\text { Xuân } \\
2011\end{array}$}} & \multirow{2}{*}{\multicolumn{2}{|c|}{$\begin{array}{l}\text { Đông } \\
2010\end{array}$}} & \multirow{2}{*}{\multicolumn{2}{|c|}{$\begin{array}{l}\text { Xuân } \\
2011\end{array}$}} \\
\hline & & & & & & & & & \\
\hline & & Hạt & $\%$ & Hạt & $\%$ & $\begin{array}{l}\text { Khối } \\
\text { lượng }\end{array}$ & $\%$ & $\begin{array}{l}\text { Khối } \\
\text { lượng }\end{array}$ & $\%$ \\
\hline 1 & Nền $+0,85$ NPK & 330,1 & 82,9 & 360,1 & 89,5 & 213,3 & 88,0 & 233,3 & 94,7 \\
\hline 2 & Nền + 1,0 NPK & 398,0 & 100 & 402,2 & 100 & 242,5 & 100 & 246,3 & 100 \\
\hline 3 & Nền + 1,15 NPK & 429,1 & 107,8 & 445,9 & 110,9 & 250.9 & 103,5 & 256,0 & 103,9 \\
\hline 4 & Nền + 1,3 NPK & 446,9 & 112,3 & 469,1 & 116,6 & 254.6 & 105,0 & 263,0 & 106,8 \\
\hline 5 & Nền + 1,45 NPK & 455.3 & 114,4 & 488,1 & 121,4 & 255.5 & 105,4 & 265,2 & 107,7 \\
\hline
\end{tabular}

Trên nền 10 tấn $\mathrm{PC} / \mathrm{ha}$, khi tăng lượng phân NPK theo cùng tỉ lệ bón cho ngô lai trung ngày trên đất xám bạc màu, đã làm tăng rõ số hạt/bắp, khối lượng 1000 hạt ở cả 2 vụ nghiên cứu (bảng 5). Vụ đồng số hạt/bắp tăng 7,8 - 14,4\% so với CT2; Vụ xuân là 10,9 - 21,4\% so với CT2; khối lượng 1000 hạt vụ đông tăng 3,5 - 5,4 \% và vụ xuân 3,9 - 7,7 \% so với CT2. Bón 1,3 NPK (CT4) cho thấy số hạt/bắp tăng 12,3 - 16,6\%; Khối lượng 1000 hạt tăng 5,0 - 6,8 \% so với CT2 ở cả 2 vụ. Trong khi chỉ thấp hơn CT5 bón 1,45 NPK là $2,1 \%-4,8 \%$ số hạt/bắp và 0,4 $0,9 \%$ về khối lượng 1000 hạt. Như vậy, CT4 cho các yếu tố cấu thành năng suất tăng cao và ổn định hơn cả.

3.3.2. Anh hương của luợng NPK bón tăng theo cùng tỉ lệ đến năng suất sinh vật và hệ số kinh tế của cây ngô

Bảng $6 a$. Ảnh hưởng của việc bón tăng lượng NPK theo cùng tỉ lệ đến các năng suất và hệ số kinh tế của cây ngô lai.

\begin{tabular}{|c|c|c|c|c|c|c|c|c|c|c|c|}
\hline \multirow{2}{*}{$\begin{array}{c}\mathrm{C} \\
\mathrm{T} \\
\mathrm{T} \\
\mathrm{N}\end{array}$} & \multirow[t]{2}{*}{ Phân bón/ha } & \multicolumn{2}{|c|}{$\begin{array}{l}\text { Năng suất hạt } \\
\text { (kg/ha) }\end{array}$} & \multicolumn{2}{|c|}{$\begin{array}{l}\text { Năng suất phụ } \\
\text { phẩm (kg/ha) }\end{array}$} & \multicolumn{2}{|c|}{$\begin{array}{l}\text { Năng suất } \\
\text { sinh vật } \\
(\mathrm{kg} / \mathrm{ha})\end{array}$} & \multicolumn{2}{|c|}{$\begin{array}{c}\text { Năng suất } \\
\text { sinh vật so với } \\
\text { CT2 }(\%) \\
\text { Tăng +; Giảm - }\end{array}$} & \multicolumn{2}{|c|}{$\begin{array}{l}\text { Hệ số } \\
\text { kinh tế }\end{array}$} \\
\hline & & $\begin{array}{l}\text { Đông } \\
2010\end{array}$ & $\begin{array}{l}\text { Xuân } \\
2011\end{array}$ & $\begin{array}{l}\text { Đông } \\
2010\end{array}$ & $\begin{array}{l}\text { Xuân } \\
2011\end{array}$ & $\begin{array}{l}\text { Đông } \\
2010\end{array}$ & $\begin{array}{l}\text { Xuân } \\
2011\end{array}$ & $\begin{array}{l}\text { Đông } \\
2010\end{array}$ & $\begin{array}{l}\text { Xuân } \\
2011\end{array}$ & $\begin{array}{l}\text { Đông } \\
2010\end{array}$ & $\begin{array}{l}\text { Xuân } \\
2011\end{array}$ \\
\hline 1 & Nền $+0,85$ NPK & $4413 a$ & $5333 a$ & 5859 & 7188 & 10272 & 12521 & $-16,1$ & $-12,6$ & 0,43 & 0,43 \\
\hline 2 & Nền + 1,0 NPK & $5470 \mathrm{~b}$ & $6652 b$ & 6778 & 7679 & 12248 & 14331 & - & - & 0,45 & 0,46 \\
\hline 3 & Nền + 1,15 NPK & $6615 \mathrm{c}$ & $7503 c$ & 7232 & 8690 & 13847 & 16193 & 13,1 & 13,0 & 0,48 & 0,46 \\
\hline 4 & Nền + 1,3 NPK & $7390 \mathrm{~d}$ & $8259 \mathrm{~d}$ & 7681 & 9313 & 15071 & 17572 & 23,0 & 22,6 & 0,49 & 0,47 \\
\hline 5 & Nền + 1,45 NPK & $7681 d$ & $8418 \mathrm{~d}$ & 8217 & 9858 & 15898 & 18276 & 29,8 & 27,5 & 0,48 & 0,46 \\
\hline & LSD5 \% & 320 & 339 & & & & & & & & \\
\hline & $\mathrm{CV} \%$ & 3,3 & 3.0 & & & & & & & & \\
\hline
\end{tabular}


Khi tăng lượng NPK cùng tỉ lệ từ 1 NPK $-1,45$ NPK bón cho ngô trồng ở mật độ 7 vạn cây/ha và khoảng cách hàng $50 \mathrm{~cm}$ đã làm tăng năng suất sinh vật 13,1 \% - 29,8 \% ở vụ đông và 13,0 - 27,5\% ở vụ xuân so với (CT2) bón 1 NPK. Điều này cho thấy tiềm năng thâm canh tăng năng suất ngô lai trung ngày trên đất xám bạc màu đặc biệt trong điều kiện áp dụng mật độ 7 vạn cây/ha và khoảng cách hàng $50 \mathrm{~cm}$ bằng tăng lượng NPK bón cho ngô theo cùng tỉ lệ.Việc giảm lượng NPK theo cùng tỉ lệ bón cho ngô từ 1 NPK xuống dù chỉ 0,85 NPK (CT1) cũng làm năng suất sinh vật cây ngô giảm 16,1 \% ở vụ đông và 12,6 \% ở vụ xuân (bảng 6a).

Hệ số kinh tế chỉ có tác dụng tốt rõ đến mức NPK, làm tăng hệ số kinh tế tương ứng ở vụ đông 2010 từ $0,48-0,49$ và ở vụ xuân 2011 từ $0,46-0,47$. Công thức bón 1,3 NPK cho hệ số kinh tế cao nhất cả 2 vụ. Giảm NPK xuống NPK (CT1) cũng làm giảm hệ số kinh tế đạt được trong trồng ngô ở cả 2 vụ nghiên cứu.

\subsubsection{Anh hưởng của việc tăng lương NPK bón đến năng suất ngô hạt}

Trên nền 10 tấn PC/ha, khi tăng lượng NPK theo cùng tỉ lệ từ $1,0-1,15-1,30-1,45 \mathrm{NPK}$ bón cho ngô đông và ngô xuân làm tăng năng suất ngô hạt từ $5470-7681 \mathrm{~kg} / \mathrm{ha}$ ở vụ đông và 6652 - $8418 \mathrm{~kg} / \mathrm{ha}$ ở vụ xuân có ý nghĩa ở mức $\mathrm{LSD}_{0,05}$ so với CT bón 0,85 NPK. Công thức bón 1,3 NPK cho năng suất ngô hạt cao hơn có ý nghĩa ở mức $\mathrm{LSD}_{0,05}$ so công thức bón $1 \mathrm{NPK}$ ở cả 2 vụ nghiên cứu. Bón đến 1,45 NPK năng suất vẫn có xu hướng tăng nhưng không có ý nghĩa thống kê so với mức bón 1,3 NPK.

Kết quả nghiên cứu ở vụ đông năm 2011 cũng tương tự các vụ trước bón 1,3 NPK đã làm tăng số hạt/ bắp, khối lượng 1000 hạt so với công thức bón 1,0 NPK, bón 1,45 - 1,60 (CT4,5) vẫn có xu hướng tăng các yếu tố cấu thành năng suất nhưng không nhiều. Năng suất ngô hạt đạt $6493 \mathrm{~kg} / \mathrm{ha}$ (CT3) bón 1,3 NPK cao hơn có ý nghĩa ở mức $\mathrm{LSD}_{0,05}$ so với $(\mathrm{CT} 1,2)$ mức bón 1 NPK và 1,15 NPK, tiếp tụ tăng lượng phân bón đến 1,45 NPK và 1,60 NPK $(C T 4,5)$, năng suất có xu hướng tiếp tục tăng nhưng không rõ (bảng 6b).

Bảng $6 b$. Ảnh hưởng của lượng bón tăng lượng NPK theo cùng tỉ lệ đến các yếu tố cấu thành năng suất và năng suất ngô lai vụ đông 2011.

\begin{tabular}{|l|l|c|c|c|}
\hline CTTN & Phân bón/ha & Số hạt/bắp & Khối lượng 1000 hạt $(\mathrm{g})$ & Năng suất hạt $(\mathrm{kg} / \mathrm{ha})$ \\
\hline 1 & Nền + 1,0 NPK & 385,9 & 209,8 & $5514 \mathrm{a}$ \\
\hline 2 & Nền +1,15 NPK & 425,2 & 219,1 & $6127 \mathrm{~b}$ \\
\hline 3 & Nền + 1,30 NPK & 442,1 & 231,5 & $6493 \mathrm{c}$ \\
\hline 4 & Nền + 1,45 NPK & 451,1 & 241,5 & $6649 \mathrm{~cd}$ \\
\hline 5 & Nền + 1,60 NPK & 462,5 & 245,1 & $6845 \mathrm{cde}$ \\
\hline LSD5 \% & & & 304 \\
\hline CV \% & & & 3,1 \\
\hline
\end{tabular}

Như vậy trên nền 10 tấn PC/ha, việc tăng lượng NPK bón chỉ nên bón đến mức $176 \mathrm{~kg} \mathrm{~N}+$ $117 \mathrm{~kg} \mathrm{P}_{2} \mathrm{O}_{5}+130 \mathrm{~kg} \mathrm{~K} \mathrm{O} / \mathrm{O}$ a trên đất xám bạc màu đã có hiệu quả kinh tế cao. 


\subsection{Anh huởng của việc tăng lương NPK đến hiệu quả kinh tế}

Bảng 7a. Ảnh hưởng của việc bón lượng NPK tăng đến hiệu quả kinh vụ đông 2010.

ĐVT: $1000 \mathrm{VNĐ/ha}$

\begin{tabular}{|l|l|c|c|c|c|c|c|c|c|}
\hline \multirow{2}{*}{$\begin{array}{l}\text { CT } \\
\text { TN }\end{array}$} & \multirow{2}{*}{ Phân bón/ha } & \multicolumn{3}{|c|}{ Chi phí } & \multicolumn{3}{c|}{ Giá trị sản phẩm } & \multirow{2}{*}{ Lãi } & $\begin{array}{c}\text { So sánh } \\
\text { lãi so với } \\
\text { CT2 +; - }\end{array}$ \\
\cline { 3 - 10 } & & Vật tư & $\begin{array}{c}\text { Lao } \\
\text { động }\end{array}$ & Tổng & Phụ phẩm & $\begin{array}{c}\text { Thươn } \\
\text { g phẩm }\end{array}$ & Tổng & & \\
\hline 1 & Nền+0,85 NPK & 12509 & 10925 & 23434 & 2344 & 28685 & 31028 & 7594 & -6068 \\
\hline 2 & Nền+1,0 NPK & 13529 & 11075 & 24604 & 2711 & 35555 & 38266 & 13662 & - \\
\hline 3 & Nền+1,15 NPK & 14570 & 11150 & 25720 & 2893 & 42998 & 45891 & 20171 & 6509 \\
\hline 4 & Nền+1,30NPK & 15589 & 11225 & 26814 & 3072 & 48035 & 51107 & 24293 & 10631 \\
\hline 5 & Nền+1,45 NPK & 16651 & 11825 & 28476 & 3287 & 49927 & 53214 & 24738 & 11067 \\
\hline
\end{tabular}

Trên nền 10 tấn PC/ha, khi bón tăng lượng NPK theo cùng tỉ lệ từ 1,15 NPK đến 1,45 NPK cho cây ngô tuy có làm tăng tổng chi phí trong trồng ngô ở cả 2 vụ lên đến 25720000 30729000 đ/ha, cao hơn khá rõ so với mức bón 1 NPK. Tuy nhiên tổng giá trị sản phẩm cũng tăng lên, từ chỗ chỉ đạt 38266000 - 46310000 đ/ha lên tới 53214000 - 58660000 đ/ha (bảng 7a, 7b). Lãi đạt từ 20171000 - 28517000 đ/ha tăng 4779000 - 11067000 đ/ha ở cả 2 vụ. Bón phân cho ngô ở mức cao hơn (1,45 NPK-CT5) tuy đem lại tổng giá trị sản phẩm cao hơn nhưng do không bù đủ chi phí đầu tư tăng thêm nên lãi đạt được thấp hơn hoặc tương đương ở mức bón $1,30 \mathrm{NPK}$. Giảm lượng NPK theo cùng tỉ lệ bón cho cây ngô từ 1 NPK xuống $0,85 \mathrm{NPK}$, làm giảm bớt chi phí sản xuất không nhiều nhưng lại làm giảm mạnh tổng giá trị sản phẩm nên làm giảm lãi $6068000-7439000$ đ/ha so với công thức bón 1 NPK. Điều này cho thấy mức bón phân 1,30 NPK $\left(176 \mathrm{~N} 117 \mathrm{P}_{2} \mathrm{O}_{5} 130 \mathrm{~K}_{2} \mathrm{O}\right)$ /ha là mức bón hợp lí nhất trong trồng ngô lai trung ngày thâm canh trên đất xám bạc màu.

Bảng $7 b$. Ảnh hưởng của việc bón tăng lượng NPK theo cùng tỉ lệ đến hiệu quả kinh tế vụ xuân 2011.

\begin{tabular}{|c|c|c|c|c|c|c|c|c|c|}
\hline & & & & & & & & \multicolumn{2}{|c|}{ ĐVT: $1000 \mathrm{VN} Đ / \mathrm{ha}$} \\
\hline \multirow{2}{*}{$\begin{array}{l}\mathrm{CT} \\
\mathrm{TN}\end{array}$} & \multirow{2}{*}{ Phân bón/ha } & \multicolumn{3}{|c|}{ Chi phí } & \multicolumn{3}{|c|}{ Giá trị sản phẩm } & \multirow{2}{*}{ Lãi } & \multirow{2}{*}{$\begin{array}{c}\text { So sánh lãi } \\
\text { so với CT2 } \\
+;-\end{array}$} \\
\hline & & Vật tư & $\begin{array}{l}\text { Lao } \\
\text { động }\end{array}$ & Tổng & $\begin{array}{l}\text { Phụ } \\
\text { phẩm }\end{array}$ & $\begin{array}{c}\text { Thương } \\
\text { phẩm }\end{array}$ & Tổng & & \\
\hline 1 & Nền $+0,85$ NPK & 13392 & 11640 & 25032 & 2875 & 34665 & 37540 & 12508 & -7439 \\
\hline 2 & Nền + 1,0 NPK & 14563 & 11800 & 26363 & 3072 & 43238 & 46310 & 19947 & - \\
\hline 3 & Nền $+1,15$ NPK & 15760 & 11880 & 27640 & 3596 & 48770 & 52366 & 24726 & 4779 \\
\hline 4 & Nền + 1,30 NPK & 16932 & 11960 & 28892 & 3725 & 53684 & 57409 & 28517 & 8570 \\
\hline 5 & Nền $+1,45$ NPK & 18129 & 12600 & 30729 & 3943 & 54717 & 58660 & 27931 & 7984 \\
\hline
\end{tabular}

Kết quả vụ đông năm 2011 tương tự như các vụ trước, trên nền 10 tấn PC/ha, khi bón tăng lượng phân NPK từ 1,15 NPK đến 1,30 NPK đã làm tăng lãi từ 2453000 - 3432000 đ/ha so với công thức bón 1 NPK. Nhưng khi tiếp tục tăng lượng phân NPK theo cùng tỉ lệ bón cho ngô tới mức 1,45 và 1,6 NPK lãi có xu hướng giảm do năng suất tăng không nhiều nên không bù đủ chi phí tăng lên do bón thêm phân (bảng $7 \mathrm{c}$ ). Như vậy xét về hiệu quả kinh tế thì công thức bón 1,30 NPK (176 kg N+117 kg $\left.\mathrm{P}_{2} \mathrm{O}_{5}+130 \mathrm{~kg} \mathrm{~K}_{2} \mathrm{O} / \mathrm{ha}\right)$ là hiệu quả nhất. 
Bảng 7c. Ảnh hưởng của việc bón tăng lượng NPK theo cùng tỉ lệ đến hiệu quả kinh tế vụ đông 2011.

\begin{tabular}{|c|c|c|c|c|c|c|c|c|c|}
\hline C & & & Chi ph & & & Tổng thu & & & $\begin{array}{l}\text { So sánh } \\
\text { d̃̃i }\end{array}$ \\
\hline $\begin{array}{l}\mathrm{T} \\
\mathrm{N} \\
\end{array}$ & Pnan bon/na & Vật tư & $\begin{array}{c}\text { Lao } \\
\text { động }\end{array}$ & Tổng & $\begin{array}{l}\text { Phụ } \\
\text { phâmm }\end{array}$ & $\begin{array}{c}\text { Thương } \\
\text { phẩm }\end{array}$ & Tổng & Lãi & $\begin{array}{c}\text { với CT1 } \\
+;-\end{array}$ \\
\hline 1 & Nền + 1,0 NPK & 14581 & 11440 & 26021 & 2719 & 35841 & 38560 & 12539 & - \\
\hline 2 & Nền + 1,15 NPK & 15757 & 12000 & 27757 & 2924 & 39826 & 42750 & 14992 & 2453 \\
\hline 3 & Nền+1,30 NPK & 16936 & 12400 & 29336 & 3102 & 42205 & 45307 & 15971 & 3432 \\
\hline 4 & Nền+1,45 NPK & 18112 & 12800 & 30912 & 3166 & 43219 & 46385 & 15473 & 2934 \\
\hline 5 & Nền+1,6 NPK & 19193 & 13600 & 32793 & 3204 & 44493 & 47697 & 14903 & 2364 \\
\hline
\end{tabular}

\section{KẾT LUẬN}

Từ những kết quả thí nghiệm nghiên cứu ảnh hưởng của việc bón tăng lượng NPK theo cùng tỉ lệ cho cây ngô lai trung ngày trên đất xám bạc màu với các mức bón từ $0,85-1 \mathrm{NPK}$ 1,15 - 1,30 NPK - 1,45 NPK, mật độ 7 vạn cây/ha, khoảng cách hàng $50 \mathrm{~cm}$ đến sinh trưởng, năng suất, sâu bệnh hại, việc hấp thu các chất dinh dưỡng chính của cây ngô, hiệu quả kinh tế của trồng ngô đã xác định mức bón phân $176 \mathrm{~kg} \mathrm{~N}+117 \mathrm{~kg} \mathrm{P}_{2} \mathrm{O}_{5}+130 \mathrm{~kg} \mathrm{~K} \mathrm{~K}_{2} \mathrm{O} / \mathrm{ha}$ (trên nền 10 tấn $\mathrm{PC}$ ) là thích hợp nhất trong thâm canh ngô lai trung ngày trên đất xám bạc màu. Năng suất đạt $6493-7390 \mathrm{~kg} / \mathrm{ha}$ vụ đông, vụ xuân lá $8259 \mathrm{~kg} / \mathrm{ha}$ cao hơn có ý nghĩa ở mức $\mathrm{LSD}_{0,05}$ so với mức bón nền $+1 \mathrm{NPK}$ hay 10 tấn PC $135 \mathrm{~kg} \mathrm{~N}+90 \mathrm{~kg} \mathrm{P}_{2} \mathrm{O}_{5}+100 \mathrm{~kg} \mathrm{~K} \mathrm{~K}_{2} \mathrm{O} / \mathrm{ha}$. Tiền lãi tăng $3432000-10631000$ đ/ha ở vụ đông và 8570000 đ/ha ở vụ xuân.

\section{TÀI LIỆU THAM KHẢO}

1. IFPRI - 2020 Projections, I. Projections, Washington, DC, 2003.

2. CIMMYT - Marianne Banziger J. H. Crouch and J. Dixon, Maize Facts and Future, 2003, pp. 22-27.

3. FAOSTAT - FAOSTAT Databases, 2007 [online], available URL: http://www.fao.org.

4. James C. - Global Status of Commercialized biotech/GM Crops 2009, ISAAA Brief 412009: Excutive Summary, 2010.

5. Tổng cục thống kê - Niên giám thống kê 2010, Nxb Thống kê, Hà Nội, 2011.

6. FAOSTAT - FAOSTAT Databases, 2011 [online], available URL: http://www.fao.org. 


\title{
ABSTRACT \\ ECONOMIC EFFICIENCY OF FERTILIZER USING FOR HYBRID MAIZE VARIETY CP 333 ON DEGRADE SOILS IN BAC GIANG PROVINCE
}

\author{
Đinh Văn Phóng ${ }^{1,}$, Nguyễn Như Hà ${ }^{2}$ Nguyễn Văn Bộ ${ }^{3}$ \\ ${ }^{l}$ CP SEEDS VietnamCompany Limited \\ ${ }^{2}$ Hanoi University of Agriculture \\ ${ }^{3}$ Vietnam Academy of Agricultural Sciences \\ "Email: phongcps@yahoo.com.vn
}

The experimental results for the hybrid maize variety CP 333 planted on the degraded, poorly organic and poorly nutritious soils in Bac Giang province showed that: On the basis of planting density of 70,000 plants per hectare and row spacing of $50 \mathrm{~cm}$, the best economic efficiency was found at fertilizer rate of 10 tons manure $+176 \mathrm{~kg} \mathrm{~N}+117 \mathrm{~kg} \mathrm{P}_{2} \mathrm{O}_{5}+130 \mathrm{~kg}$ $\mathrm{K}_{2} \mathrm{O}$ per hectare. With that rate of fertilizerthe growth of spring maizecould reach a yield of $8260 \mathrm{~kg}$ per hectare while that of winter maize could yield at 6493 - $7390 \mathrm{~kg}$ per hectare (average: $6941 \mathrm{~kg}$ per hectare). The benefit gained by spring maize growth was estimated to be $28,517,000$ VND per hectare and and that of winter maize was of 15,971,000 - 242,93,000 VND per hectare.

Keywords: hybrid maize, degraded soils, fertilizer. 